\title{
Aspectos genéticos do peso à desmama e de algumas características reprodutivas de fêmeas Nelore
}

[Genetic aspects of weaning weight and some reproductive traits in Nellore cattle]

\author{
M.G.M. Gressler ${ }^{1}$, J.C.C. Pereira ${ }^{2,5 *}$, J.A.G. Bergmann ${ }^{2,5}$, V.J. Andrade ${ }^{2}$, M.F. Paulino ${ }^{3}$, S.L. Gressler ${ }^{4}$ \\ ${ }^{1}$ Mestre em Zootecnia \\ ${ }^{2}$ Escola de Veterinária da UFMG \\ Caixa Postal 567 \\ 30123-970 - Belo Horizonte, MG \\ ${ }^{3}$ Universidade Federal de Viçosa \\ ${ }^{4}$ Doutorando em Ciência Animal - EVUFMG \\ ${ }^{5}$ Bolsista do $\mathrm{CNPq}$
}

\begin{abstract}
RESUMO
Estimaram-se os parâmetros genéticos do peso à desmama ajustado para 240 dias de idade $\left(\mathrm{PD}_{240}\right)$, da idade ao primeiro parto (IPP), da idade ao segundo parto (ISP) e do primeiro intervalo de partos (PIEP) em animais da raça Nelore, pelo método da máxima verossimilhança restrita, utilizando-se o aplicativo MTDFREML, sob modelo animal. As estimativas de herdabilidade incluindo somente uma variável foram: $0,48 \pm 0,20 ; 0,27 \pm 0,15 ; 0,14 \pm 0,16$; e $0,03 \pm 0,13$, respectivamente, para $\mathrm{PD}_{240}$, IPP, ISP e PIEP. As correlações genéticas estimadas entre IPP e ISP e PIEP foram de 0,97 e $-0,92$, respectivamente. A correlação genética entre ISP e PIEP foi de $-0,82$. As correlações genéticas entre $\mathrm{PD}_{240} \mathrm{e}$ IPP, ISP e PIEP foram $-0,20,0,00$ e 1,00 , respectivamente.
\end{abstract}

Palavras-chave: bovino, correlação genética, herdabilidade

\begin{abstract}
Estimates of genetic parameters for weaning weight adjusted to 240 days of age $\left(W W_{240}\right)$, age at first calving (AFC), age at second calving (ASC) and first calving interval (FCI) in Nellore cattle using REML methodology (MTDFREML), were obtained. Heritability estimates from univariate analyses were: $0.48 \pm 0.20 ; 0.27 \pm 0.15 ; 0.14 \pm 0.16$; and $0.03 \pm 0.13$, for $W W_{240,} A F C, A S C$ and $F C I$, respectively. Genetic correlation estimates between $A F C$ and $A S C$ and $A F C$ and $F C I$ were 0.97, -0.92 , respectively. The genetic correlation between ASC and FCI was -0.82. The genetic correlations between $W W_{240}$ and AFC, $A S C$ and FCI were $-0.20,0.00$ and 1.00, respectively.
\end{abstract}

Keywords: cattle, genetic correlation, heritability

\section{INTRODUÇÃO}

Estratégias seletivas que visem equilibrar características de crescimento, avaliadas pelos pesos e ganhos de peso às várias idades, e características reprodutivas são desejáveis tanto no aspecto genético como no econômico. De acordo com Cartwright (1970), os sistemas de produção de bovinos de corte são caracterizados por antagonismo genético entre o aumento da taxa de crescimento até a idade de abate, na fase de produção, e a redução das exigências

Recebido para publicação em 7 de julho de 2004

Recebido para publicação, após modificações, em 14 de dezembro de 2004

*Autor para correspondência (corresponding author)

E-mail: jonas@vet.ufmg.br 
nutricionais das matrizes do rebanho na fase de reprodução.

Características de crescimento (pesos e ganhos de peso) têm sido consideradas como prioritárias na seleção em bovinos de corte. Alguns autores têm observado antagonismo genético entre pesos em várias idades e características de eficiência reprodutiva em fêmeas (Mariante e Zancaner, 1985; Barbosa, 1991). Outros estudos revelaram que essas características são pouco relacionadas (Smith et al., 1989) ou são até mesmo favoravelmente (negativamente) relacionadas (Mercadante, 1995; Garnero et al., 2001).

Este trabalho teve o objetivo de estudar as relações genéticas entre o peso à desmama e características reprodutivas (idades ao primeiro e ao segundo partos e primeiro intervalo de partos), de animais da raça Nelore.

\section{MATERIAL E MÉTODOS}

O estudo foi desenvolvido com informações referentes a um grupo de animais do rebanho pertencente à Fazenda Minuano, localizada no município de Nioaque, Sudoeste do estado de Mato Grosso do Sul.

A formação do rebanho iniciou-se em 1982. Nos primeiros anos não havia estação de monta, implantada em 1991. Durante os anos estudados, a estação de monta da propriedade não foi bem definida. Sua duração inicial, de seis meses, foi reduzida com o decorrer dos anos. A data de início da estação não foi fixada, e variou em função da pluviosidade de cada ano. Em geral, o início ocorreu em setembro e outubro de cada ano. As crias foram desmamadas em torno dos oito meses de idade, e o manejo profiláticosanitário consistiu de práticas comuns aos rebanhos de cria de bovinos de corte.

Os animais foram criados desde o nascimento em regime exclusivo de pasto, onde receberam suplementação mineral. Devido ao fato de o rebanho se encontrar em expansão, durante os anos estudados a pressão de seleção aplicada foi pequena. As informações utilizadas foram coletadas entre 1991 e 2002, com a inclusão de animais nascidos entre 1991 e 1998.
As características analisadas foram: peso das fêmeas à desmama ajustado para 240 dias (P240; $\mathrm{N}=552$ ), idade ao primeiro parto (IPP; $\mathrm{N}=607$ ), idade ao segundo parto (ISP, $\mathrm{N}=431$ ) e primeiro intervalo de partos (PIEP; $\mathrm{N}=431$ ). Utilizou-se o pacote estatístico Statistical Analysis System (User's... 1999), para a formação de arquivos, consistência e análise descritiva dos dados, assim como para a verificação do efeito de fatores não genéticos sobre as características estudadas.

As estimativas dos componentes de (co)variância foram obtidas pelo método da máxima verossimilhança restrita livre de derivadas sob o modelo animal. Utilizou-se o programa Multiple Trait Derivative-Free Restricted Maximum Likelihood desenvolvido por Boldman et al. (1995). A escolha do modelo apropriado baseouse nas informações referentes aos efeitos ambientes, investigados previamente. Foram realizadas análises unicaráter e bicaráter de todas as características, utilizando-se um modelo completo que incluiu como os efeitos fixos de grupo contemporâneo (ano e mês de nascimento do animal) para todas as características e como covariável o efeito linear do peso ao nascer do primeiro bezerro para IPP e efeito linear do peso ao nascer do segundo bezerro para ISP e PIEP.

Para todas as características o modelo geral utilizado foi:

$\hat{\mathrm{Y}}=\mathrm{X} \beta+\mathrm{Zu}+\mathrm{e}$, em que:

$\mathrm{Y}=$ vetor de observações (variáveis dependentes);

$\mathrm{X}=$ matriz de incidência associada aos efeitos fixos;

$\mathrm{Z}=$ matriz de incidência associada aos efeitos aleatórios;

$\beta=$ vetor de soluções para os efeitos fixos;

$\mathrm{u}=$ vetor de valores genéticos aditivos;

$\mathrm{e}=$ vetor de efeitos residuais.

$O$ vetor de observações correspondeu, nas análises de características únicas, a uma das quatro características: peso à desmama ajustado para 240 dias; idade ao primeiro parto; idade ao segundo parto e primeiro intervalo de partos. Nas análises com duas características, o vetor de observações incluiu a idade ao primeiro parto e o primeiro intervalo de partos, a idade ao primeiro parto e a idade ao segundo parto, a idade ao segundo parto e o primeiro intervalo de partos. 
Realizou-se também a análise conjunta do peso à desmama ajustado para 240 dias e deste com cada uma das características reprodutivas (IPP, PIEP, ISP).

A cada ciclo, o programa era reiniciado, utilizando-se como valores de (co)variâncias iniciais aqueles obtidos na análise anterior. Esse procedimento repetiu-se até que os componentes estimados não diferissem entre uma análise e outra, de acordo com as recomendações de Boldman et al. (1995), ou seja, quando a variância do Simplex foi inferior a $10^{-9}$.

\section{RESULTADOS E DISCUSSÃO}

Na Tab. 1 são apresentadas as estimativas dos componentes de variância e as herdabilidades para as quatro características estudadas. A herdabilidade estimada para peso à desmama foi mais elevada do que as relatadas por Mercadante (1995) e Garnero et al. (2001), que obtiveram resultados de 0,29 e 0,26, respectivamente. Valores mais próximos foram relatados por Martins. et al. (1998) e Biffani et al. (1999), $0,42,0,48$, respectivamente. O valor estimado do coeficiente de herdabilidade sugere que a seleção pode promover ganhos genéticos apreciáveis mediante a seleção para a característica.

Tabela 1. Herdabilidade $\left(\mathrm{h}^{2}\right) \pm$ erro-padrão (EP) e componentes de variância para peso à desmama ajustado para 240 dias de idade $\left(\mathrm{PD}_{240}\right)$, idade ao primeiro parto (IPP), idade ao segundo parto (ISP) e primeiro intervalo de partos (PIEP) obtidos por meio de análises unicaráter

\begin{tabular}{lcccc}
\hline Característica & $h^{2} \pm \mathrm{EP}$ & $\sigma_{\mathrm{A}}^{2}$ & $\sigma_{\mathrm{E}}^{2}$ & $\sigma_{\mathrm{F}}^{2}$ \\
\hline $\mathrm{PD}_{240}$ & $0,48 \pm 0,201$ & 241,875 & 259,386 & 501,195 \\
$\mathrm{IPP}$ & $0,27 \pm 0,151$ & 6,319 & 17,226 & 23,546 \\
$\mathrm{ISP}$ & $0,14 \pm 0,169$ & 3,890 & 24,478 & 28,360 \\
$\mathrm{PIEP}$ & $0,03 \pm 0,135$ & 0,497 & 18,260 & 18,756 \\
\hline$\sigma^{2}{ }_{\mathrm{A}}=$ variância genética aditiva, $\sigma_{\mathrm{E}}^{2}=$ variância residual, $\sigma_{\mathrm{F}}^{2}$ \\
$=$ variância fenotípica
\end{tabular}

A estimativa de herdabilidade obtida para idade ao primeiro parto situa-se dentro do intervalo de valores freqüentemente relatados por diversos autores para a característica na raça Nelore. Estimativas muito próximas foram obtidas por Lôbo (1998) e Dias (2001), 0,29 e 0,20, respectivamente.
A herdabilidade estimada para ISP revelou-se inferior às relatadas por Barbosa (1991), 0,34, na raça Canchim, Winkler (1993), 0,39 na raça Guzerá, e superior à estimativa de 0,04 obtida por Silva et al. (2000) na raça Canchim. Percebese que a característica apresenta herdabilidade bastante variável, apesar da limitação imposta pelo número restrito de pesquisas sobre $\mathrm{o}$ assunto.

Para primeiro intervalo de partos, o valor do coeficiente de herdabilidade estimado foi baixo e muito próximo ao relatado por Pereira et al. (2000) que encontraram valor de 0,04 , e superior ao mencionado por Biffani et al. (2000), 0,01. No entanto, a estimativa foi menor que a de Mercadante (1995) e Gressler (1998), ambos 0,10, e de Simioni (2002), 0,09. O valor estimado da herdabilidade para primeiro intervalo de partos indica que a variável é pouco influenciada por genes de ação aditiva e muito influenciada pelo meio ambiente e por genes de ação não-aditiva.

As estimativas dos componentes de variância e covariância e as correlações genéticas, obtidas a partir de análises com duas variáveis, entre IPP e ISP e PIEP são apresentadas na Tab. 2. Os componentes de variância estimados pelas análises com duas características foram muito semelhantes aos das análises com características únicas.

Constatou-se associação genética negativa entre idade ao primeiro parto e primeiro intervalo de partos. Este resultado difere dos encontrados por Mariante e Zancaner (1985) e Mercadante (1995), que mencionaram associação positiva entre as duas características. Associação negativa foi relatada por Ramos (1979) e Haile-Mariam e Kassa-Mersha (1994). As estimativas de correlações fenotípicas e ambientes também foram negativas. A correlação residual indica que os fatores de ambiente influenciaram a idade ao primeiro parto e o primeiro intervalo de partos de maneira adversa. Resultados semelhantes foram encontrados por Mercadante (1995).

A correlação genética verificada entre a idade ao primeiro parto e a idade ao segundo parto foi de 0,97, sugerindo que a maioria dos genes que atuam sobre a primeira característica também têm efeito, no mesmo sentido, sobre a segunda. As correlações fenotípica e residual foram 
A partir da correlação genética entre o peso à desmama e a idade ao primeiro parto e da maior herdabilidade do peso à desmama, pode-se sugerir que a seleção de bezerras mais pesadas aos 240 dias de idade poderia levar à obtenção de animais mais jovens ao primeiro parto nesse rebanho, o que é desejável na pecuária de corte.

A correlação entre peso à desmama e idade ao segundo parto revelou que, para esse grupo de dados, não houve associação genética entre essas características, indicado pelo valor nulo da correlação genética $\left(\mathrm{r}_{\mathrm{A}}=0,00\right)$ e pelos baixos valores, próximos de zero, das estimativas de correlações residual e fenotípica $(-0,05,-0,03$, respectivamente).

Informações disponíveis na literatura são raras. Barbosa (1991) obteve correlações genética, residual e fenotípica de $-0,09,-0,11,-0,10$. Em função da escassa literatura que aborda a idade ao segundo parto, a interpretação mais aprofundada sobre o resultado obtido fica prejudicada pela impossibilidade de se cotejar com outros pesquisadores.

A análise inferencial dos parâmetros genéticos obtidos permite supor que o conjunto de genes que atua sobre a idade ao primeiro parto e o peso à desmama podem não atuar da mesma maneira sobre a idade ao segundo parto.

A correlação genética igual à unidade entre o peso à desmama e o primeiro intervalo de partos pode ser explicada de modo semelhante às justificativas de Boldman et al. (1995), segundo as quais, em conjuntos de dados com número reduzido de informações, existe tendência para convergência das correlações genéticas em valores próximos da unidade. Além disso, o primeiro intervalo de partos apresentou variância genética próxima de zero.

Correlações positivas e desfavoráveis entre essas características também foram relatadas por Mariante e Zancaner (1985), 0,81, sugerindo que o aumento do potencial genético para tamanho (peso) estaria associado a intervalos de partos mais longos. Mercadante (1995) também relatou correlação genética desfavorável, embora de menor magnitude, entre essas características $(0,06)$.
Ressalta-se que as correlações genéticas estimadas devem estar associadas a elevados erros-padrão. Segundo VanVleck e Henderson (1961), pode haver baixa precisão das estimativas de correlação genética quando uma das características envolvidas é de baixa herdabilidade.

\section{CONCLUSÕES}

As estimativas de herdabilidade obtidas sugerem que a seleção deve resultar em progresso genético para o peso à desmama e para as idades ao primeiro e ao segundo partos. $\mathrm{O}$ baixo valor encontrado para o intervalo de partos evidencia pouca variação genética aditiva e grande influência de fatores não genéticos na sua manifestação. A elevada correlação genética entre as idades ao primeiro e ao segundo partos sugere que a seleção para uma delas resultará em melhoramento também da outra. $\mathrm{O}$ valor estimado de correlação genética entre o peso à desmama e a idade ao primeiro parto foi negativo e favorável, indicando sinergismo genético entre essas características.

\section{REFERÊNCIAS BIBLIOGRÁFICAS}

BARBOSA, P.F. Analise genético-quantitativa de características de crescimento e fertilidade em fêmeas da raça Canchim. 1991. 237f. Tese (Doutorado em Ciências)- Faculdade de Medicina de Ribeirão Preto, Universidade de São Paulo, Ribeirão Preto.

BIFFANI, S.; MARTINS FILHO, R.; LUCIFERO, M. et al. Características reprodutivas de fêmeas da raça Nelore criadas na região Nordeste do Brasil. In: REUNIÃO ANUAL DA SOCIEDADE BRASILEIRA DE ZOOTECNIA, 37., 2000, Viçosa. Anais... Viçosa: SBZ, 2000. p.202.

BIFFANI, S.; MARTINS FILHO, R.; MARTINI, A. et al. Fatores ambientais e genéticos que influenciam o desenvolvimento ponderal até o desmame de animais criados no Nordeste do Brasil. Rev. Bras. Zootec., v.28, p.693-700, 1999.

BOLDMAN, K.G.; KRIESE, L.A.; VAN VLECK, L.D. et al. A manual for use for MTDFREML. A set of programs to obtain estimates of variance and covariance [DRAFT]. Lincoln: Department of Agriculture / Agricultural Research Service, 1995. $120 \mathrm{p}$.

BOURDON, R.M.; BRINKS, J.S. Genetic, environmental and phenotypic relationships among 
gestation length, birth weight, growth traits and age at first calving in beef cattle. J. Anim. Sci., v. 55, p. 543$553,1982$.

CARTWRIGHT, T.C. Selection criteria for beef cattle for the future. J. Anim. Sci., v.30, p.706-711, 1970.

DIAS, D.S.O Análise genética de características de crescimento e de reprodução de animais da raça Nelore criados na região Centro-Oeste do Brasil. 2001. 117f. Tese (Doutorado em Zootecnia)Faculdade de Ciências Agrárias e Veterinárias de Jaboticabal, Universidade Estadual Paulista, Jaboticabal, SP.

GARNERO, A.V.; GUNSKI, R.J.; SCHWENGBER, E.B. et al. Comparación entre critérios de selección para características de crecimiento correlacionados com edad al primer parto en la raza Nelore. Liv. Res. Rural Develop., v.13, 2001. Disponível em: $<$ http://www.cipav.org.co/lrrd13/2/garn132.htm>. Acessado em 12/01/2003.

GRESSLER, S.L. Estudo de fatores de ambiente e parâmetros genéticos de algumas características reprodutivas em animais da raça Nelore. 1998. 149f. Dissertação (Mestrado em Zootecnia)- Escola de Veterinária, Universidade Federal de Minas Gerais, Belo Horizonte.

HAILE-MARIAM, M.; KASSA MERSHA, H. Genetic and environmental effects on age at first calving interval of naturally bred Boran (zebu) cows in Ethiopia. Anim. Prod., v.58., p.329-334, 1994.

LÔBO, R.N.B. Parâmetros genéticos para características reprodutivas de vacas Zebu na região semi-árida do Brasil. In: REUNIÃO ANUAL DA SOCIEDADE BRASILEIRA DE ZOOTECNIA, 35. 1998, Botucatu. Anais... Botucatu: SBZ, 1998. p.309311.

MARIANTE, A.S.; ZANCANER, A. Crescimento $e$ reprodução em gado Nelore. Visão do criador e do pesquisador. São Paulo: Ed. Criadores, 1985. 152p.

MARTINS, G.A.; MARTINS FILHO, R.; LIMA, F.A.M. et al. Influência de fatores genéticos e de meio sobre o crescimento de bovinos da raça Nelore no estado do Maranhão. In: REUNIÃO ANUAL DA SOCIEDADE BRASILEIRA DE ZOOTECNIA, 35., 1998, Botucatu. Anais...Botucatu: SBZ, 1998. p.431433.

MERCADANTE, M.E.Z. Estudo das relações genético-quantitativas entre características de reprodução, crescimento e produção em fêmeas da raça Nelore. 1995. 90f. Dissertação (Mestrado em Ciências)- Faculdade de Medicina de Ribeirão Preto, Universidade de São Paulo, Ribeirão Preto, SP.

MEYER, K. Estimating variances and covariances for multivariate animal models by restricted maximum likelihood. Genet. Sel. Evol., v.23, p.67-83, 1991.

PEREIRA, E.; ELER, J.P.; FERRAZ, J.B.S. Análise genética do intervalo de partos e primeiro intervalo de partos na raça Nelore. In: SIMPÓSIO NACIONAL DA SOCIEDADE BRASILEIRA DE MELHORAMENTO ANIMAL, 3., 2000, Belo Horizonte. Anais... Belo Horizonte: SBMA, 2000. p.433-434.

RAMOS, A.A. Estudo genético-quantitativo das caracteristicas reprodutivas e produtivas de um plantel da raça Gir. 1979. 242f. Tese (Doutorado em Ciências)- Faculdade de Medicina de Ribeirão Preto, Universidade de São Paulo, Ribeirão Preto, SP.

SILVA, A.M.; ALENCAR, M.M.; FREITAS, A. R. et al. Herdabilidades e correlações genéticas para peso e perímetro escrotal de machos e características reprodutivas e de crescimento de fêmeas, na raça Canchim. Rev. Bras. Zootec., v.29, p.2223-2230, 2000 (suplemento 2).

SIMIONI, V.M. Estudo genético-quantitativo de algumas características reprodutivas na raça Nelore. 2002. 40f. Tese (Doutorado em Zootecnia)- Faculdade de Ciências Agrárias e Veterinárias de Jaboticabal, Universidade Estadual Paulista, Jaboticabal, SP.

SMITH, B.A.; BRINKS, J.S.; RICHARDSON, G.V. Estimation of genetics parameters among reproductive and growth traits in yearling heifers. J. Anim. Sci., v.67, p.2886-2891, 1989 .

USER'S guide: statistics. Version 8. Cary, NC: SAS Institute, 1999.

VAN VLECK, L.D.; HENDERSON, C.R. Empirical sampling estimates of genetic correlations. Biometrics, v.17, p.359-371, 1961.

WINKLER, R. Tamanho corporal e suas relações com algumas características reprodutivas em fêmeas bovinas adultas da raça Guzerá. 1993. 115f. Dissertação (Mestrado em Zootecnia)- Escola de Veterinária, Universidade Federal de Minas Gerais, Belo Horizonte. 